BPMJ

22,2

1

Received 14 May 2015 Revised 1 August 2015 28 September 2015 Accepted 26 October 2015

\section{Strategic orientation and information technological turbulence}

\section{Contingency perspective in SMEs}

\author{
Aluisius Hery Pratono \\ Faculty of Business and Economics, Universitas Surabaya, \\ Surabaya, Indonesia
}

\begin{abstract}
Purpose - There is an emerging recognition in the strategy field that differences in organization forms represent firms' capability to gain benefit from investing in technology. This study has intention to add to this stream of research by proposing the technological turbulence (TT) as a primary contingency factor focussing on strategic orientation (SO) as main determinant of firm performance (FP). The purpose of this paper is to provide considerable suggestion on how to match $\mathrm{SO}$ with various level of TT.

Design/methodology/approach - This study uses quantitative approach with structural equation model to understand the moderating effect of information TT on the relationship between SO and FP. The 390 small and medium enterprises (SMEs) in Indonesia contributes to the research as randomly selected respondents.

Findings - The result shows how the TT influences managerial decision-making processes under an opportunity-based paradigm. However, SME managers face lack of capability to deal with high TT. Research limitations/implications - This study uses cross-section data at the SMEs context in Indonesia.

Practical implications - This study suggest that the initiative to encourage SMEs to adopt information technology (IT) should consider the SME capability to utilize the IT.

Originality/value - The research gap challenges a question from previous literature on how long firms retain a given capability to deal with dynamic environment. This study has intention to add to the stream of research by proposing the information TT as a primary contingency factor focussing on $\mathrm{SO}$ as main determinant of FP.
\end{abstract}

Keywords Performance, Business strategy, Small enterprizes, Information technology, Contingency theory

Paper type Research paper

\section{Introduction}

There is an emerging recognition in the strategy field that differences in organization forms represent firms' capability to gain benefit from investing in technology (Kapoor and Lee, 2013). The idea of the "Internet of Things" is expected to provide more opportunities to small and medium enterprises (SMEs) rather than a burden. However, the silence technology encompasses a vast growing network from various industries, which brings fundamental change on the way SME works (Li et al., 2013).

The combination between increasing available of network data and substantial technology improvements has triggered firms in investing in information technology (IT) (Risselada et al., 2014). Therefore, strategic orientation (SO) has two options: firms set their strategy by opportunities or by resources (Gürbüz and Aykol, 2009). Firms are considered to be more entrepreneurial if their strategic actions are driven by opportunity than by resources (Bradley et al., 2011).
Business Process Management Journal Vol. 22 No. 2, 2016 pp. 1-15 (c) Emerald Group Publishing Limite 1463-7154 DOI 10.1108/BPMJ-05-2015-0066 
SMEs may expect greater performance, if their resource allocation is more ambitiously innovative (Klingebiel and Rammer, 2014). However, the relationship between return of SO and firm performance (FP) could be heterogeneous due to differences in expectation on the value of resource availability (Kunc and Morecroft, 2010). Technological capability increases firms' expectation to achieve greater performance (Ruiz-Ortega et al., 2013).

SMEs may make substantial investment in R\&D through utilizing radical technological turbulence (TT), but may pursue inferior technology to leverage their assets (Wu et al., 2014). The dynamic capability offers more complicated effects on FP under dynamic business environment, ranging from stable to very dynamic environmental settings (Schilke, 2014).

More recently, researchers concern on contingency factors that influence the effect of TT. Hence, IT allows SMEs to develop their capability in various fields, including alliances, product development, marketing, and mergers. SMEs need to understand the stage of competitive advantage as well as their capability to manage an innovation under high environmental turbulence, since many firms are short lived (McGrath, 2013). The research gap from previous literature challenges a question on how long firms retain a given capability to deal with dynamic environment (Schilke, 2014).

This study has intention to add to this stream of research by proposing the TT as a primary contingency factor focussing on $\mathrm{SO}$ as main determinant of FP. The result is expected to provide considerable suggestion on how to match SO with various level of TT. To accomplish this purpose, this study conceptualizes SO in terms of opportunitybased perspective, thus make this measurable and distinct from resource-based orientation (Gürbüz and Aykol, 2009). Hence, the difference level of TT is considered as moderating effect.

\section{Literature review}

This study considers both contingency theory and resource-based view as underpinning theories to support the hypothesis. As the study concerns on the impact of information TT on the relationship between SO and FP, the review on contingency theory and resource-based view briefly discusses to illustrate their significance.

\subsection{Contingency theory}

This study adopts contingency approach to understand the impact of SO on SME performance in the context of dynamic TT. The theory has emerged to criticize the classical management theory from neglecting contingency factors. It is acknowledge that both Max Weber with bureaucracy theory and Frederic Taylor with scientific management theory pay too much attention on internal organization (Pheng and Shang, 2011). The basic premise of contingency theory is that firms achieve the best performance when their structures is relevant to deal with the contingencies imposed by their size, technology, and environment (Donaldson, 1995).

Contingency theory has intention to understand how firms align their expected performance with both internal and external business environment (Homburg et al., 2012). This theory views that external environment is key determinant to FP. As organization, firms are amenable to the influence of business environment. Specifically, this theory lays emphasis on questions on whether and under which contingency variables contribute to FP. Hence, it is necessary that firms do not only acquire and develop their resources but also need to enhance the capability to deal with environmental turbulence.

Contingency-based organizations gain competitive advantage through assessing their business environment and set strategy, which are appropriate for each level of

$\begin{array}{r}\text { Strategic } \\ \text { orientation and } \\ \text { information } \\ \mathrm{TT} \\ 2 \\ \hline\end{array}$


BPMJ

22,2

environmental turbulence (Johannesson and Palona, 2010). That involves integration whole in firm's interactions with business environment. That presents dynamic capability is equated with environmental turbulence (Schilke, 2014). Hence, contingency theory indicates behavior of firms, which is necessary for survival.

Firms are considered as contingency-based organization when adapting to business environment, such as a choice of product market domain to deal with entrepreneurial problem, choice of innovation to deal with engineering problem, and reducing uncertainty to overcome administration problem (Puranam et al., 2014). The generic contingency factors include implementing strategy, organization size and structure, information system (Jääskelainen et al., 2012).

Size and structure: contingency theory considers that bureaucracy theory as "iron cage" due to imposing too much on efficiency issue with some ambivalent analysis, such as specialization, formal rule, procedure, and scientific performance appraisal. The classical management approach concerns to threaten workers as machine (Bell and Martin, 2012). In the context of SMEs, greater involvement of owner managers is important for the role of managers, while the control system, compliance and shareholder value may encourage firms to be more risk-aversion, focus on short-term efficiency and less focus on innovation (Bazemer et al., 2012).

Strategy: the business environment of SMEs indicates interdependent activities with their customers, suppliers, partners, and competitors. Under some condition, resource similarity among small firms influences their intention to conduct partnership (Cui, 2013). The contingent effect of resource similarity implies on portfolio management with resource diversity toward partnership stability. Firms with integrative strategy tend to control and improve coordination among their complementary activities, while firms pursuing alliances have more intention to invest new technologies (Kapoor and Lee, 2013). Firms with changing competitive strategy to deal with environmental turbulences require changing their organizational structure to become more flexible and adaptive (Park and Kruse, 2014).

Information system: Changes in technology encourage firms to take advantage of new opportunities. Access to superior technological capabilities drives firms to be more proactive, which implies on entrepreneurial behavior to identify and achieve opportunities (Ruiz-Ortega et al., 2013).

\subsection{Resource-based theory}

Dynamic capability theory has emerged to develop the classical resource-based theory. The resource based theory has intention to understand how firms value-creating strategies meet dynamic environment to achieve sustainable FP (Eisenhardt and Martin, 2000). The classical RBT presume that firm requires recruitment of more such resources in order to achieve competitive advantage (Penrose, 1959). This resource includes valuable assets, capabilities, and information that firms control to conceive and implement their strategy (Barney, 1991).

This theory underlines the condition under which firms can gain the best performance. Along with broaden perspective of global sustainability, such performance is considered to be superior profit if it meets a sustainable competitive advantage. There are two main concepts, which are expected to bring superior performance, namely, resources and capability (Bell and Martin, 2012).

In the context of entrepreneurship theory, there are at least two dominant strands: Kirznerian and Schumpeterian. The Kirzenerian considers discovery process over business opportunities while innovation is associated with Schumpeterian school of thought (Sundqvist et al., 2012). For Schumpeter, external variables are considered to 
uncontrollable at the micro-level, while the idea to seize opportunities spring from internally induced change (Betta et al., 2010).

Dynamic capabilities are acknowledged as strategic options, which SMEs to allocate their controlled resources when the opportunity comes (Schilke, 2014). Strategic awareness is acknowledged as a specific capability, which implies on shaping the strategic posture of the firms. SMEs view their strategic plan, as strategic awareness, which underlines the rational actions and choices, is imperative to their performance (Wiesner and Millet, 2012).

Enhancing dynamic capability implies serious costs (Schilke, 2014). Firms with honorable intention to change may achieve greater performance than their competitor, as they deploy significant resources to develop their capabilities. Asset retrenchment as deliberately reducing cost with aim of increasing efficiency mainly targets capability development activities, including research and development (Lim et al., 2013). The balance between controlled resources and dynamic capabilities comes to a challenging question, as there is risk of a failure in development of resources to firm capabilities (Huesch, 2013).

\section{Hypothesis development}

There are various definitions of strategy in the literatures. The early definition argues that strategy is a consistency in organization behavior to achieve their purposes (Mintzberg and Waters, 1985). Strategy is also considered as a mechanism on how firms' focus on effort in order to achieve the expected performance (Wiesner and Millet, 2012). This study considers the concept of SO as the way firms create strategy, which could be based on opportunity or resources (Gürbüz and Aykol, 2009). Entrepreneurial firms outline business opportunities as main reason to set their strategy.

Opportunity-driven strategy designs opportunity-seeking behavior in decisionmaking process. This concept is embedded in entrepreneurial leader in which enables SMEs to be more flexible to seize opportunities (Kansikas et al., 2012). This strategy pertains to firm responsiveness to emerging issues raised by stakeholders, e.g. emission reduction, governance reform, and fair labor practices. The issue becomes salient after the firms interpret the environment turbulence through the rational pursuit of their goals or managerial cognition (Bundy et al., 2013).

They way how firms deploy their resources shows greater intention of the firms to achieve the best performance (Klingebiel and Rammer, 2014). Entrepreneurial firms have more commitment to opportunity with willingness and ability to seize opportunities in the market (Bradley et al., 2011). Firms with greater SO have more ambitious to gain the opportunities and prefer to rent the required resources. Driven by perception of opportunity, entrepreneurial firms enhance their capability to respond the external environment that brings signal opportunities and act upon those it to achieve performance:

\section{H1. SO has direct impact on FP.}

A better understanding of the condition under which SO is expected to impact on FP requires a contingency factor that lays emphasizes the various level of TT. Environmental turbulence represents a process that alters the impact of the independent variables on FP in the context of contingency theory. Previous literatures view environmental turbulence as exogenous variable, which provides moderating effect (see Zhang and Duan, 2010; Wang and Fang, 2012; Sundqvist et al., 2012; and Chi and Sun, 2012).

IT offers new ways to reach the customers with substantial market information. Firms gain benefit from social influence on direct marketing, which implies on the

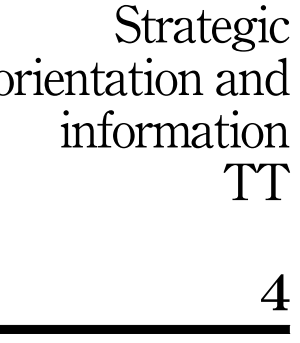


BPMJ

22,2

greater intention to collect information on social networks of customers (Risselada et al., 2014). IT also allows firms to develop their capability in various fields, including alliances, product development, marketing, and mergers (Schilke, 2014).

Investment in technology allows firms to develop their capabilities with active information acquisition, i.e. multiple channels, customers' voice incorporation, and rapid information dissemination (Kumar et al., 2011). IT and other departments including external bodies, users, monitoring system, and support teams may provide valuable information concerning incidents and possible threats. Specifically, technology turbulence fosters "energetic will," which enable firms to create new innovation (Betta et al., 2010).

Defining IT as a moderating variable offers a holistic conceptual of technological business value (Cao et al., 2011). IT brings performance when firms can properly combine with other organizational factors, including SO. The technology is often defined as a moderating variable that creates FP through such organizational factor, which is understood as resource complementary. Investment in IT allows SMEs to gain information on customer needs, which may alert firms to new market and technology development into business value (Zhang and Duan, 2010). A combination between customer group and IT can leverage firms' performance to increase their performance (Luo et al., 2014).

On the other hand, firms with SO and more ambitious on innovation have to deal with higher risk of decision-making error. Deploying resources for opportunityoriented strategy may enhance business risk (Zhang and Duan, 2010). As TT challenges SMEs' capability to adapt the market changes, the inability to respond to opportunities has led demise of many firms (Kumar et al., 2011).

Unpredictable and uncertain business environment, the wide variety of information becomes not valuable as firms fail to understanding and identifying different kinds of knowledge (Wang and Fang, 2012). IT provides various alternatives to the customers, who expect a certain quality of products from other firms. The benefit from TT is diminished as industry provides various substitution products. Based on the previous theoretical arguments of diminishing firms' capability, this study hypothesis that TT moderates the relationship between SO and FP. Hence:

H2. TT has moderating effect on the relationship between SO and FP.

H2a. Under high TT, SO has positive impact on FP.

H2b. Under low TT, SO has negative impact on FP.

\section{Research Method}

\subsection{Data}

This study uses quantitative method with cross-section design. The information analysis springs from a list of questionnaires, which distributed through random sampling approach to obtain maximum respond rate. The questionnaires design adapts from some literatures with aims to collect accurate information from respondents. The measure of SO is adapted from Bradley et al. (2011), while the TT is adapted from Zhang and Duan (2010). Table I provides the items of measurement.

Turning to the unit analysis, the observed population of this research concerns on SMEs in Surabaya City, Indonesia. The reason lies behind the observed population refers to the pivotal role of SMEs in the local economy. The concept of SMEs refers to the local regulation that is Law No 20/2008. The regulation sets three groups of SMEs, micro, SMEs. Micro enterprises have criteria with sales less than Rp300 million and 


\begin{tabular}{|c|c|c|c|}
\hline Latent variables & Items & Descriptions & Strategic \\
\hline \multirow[t]{8}{*}{ Firm performance $(\mathrm{FP})$} & FP1 & Sales growth at the last three years & informatior \\
\hline & FP2 & Sales growth comparison with direct competitors & \\
\hline & FP3 & Employment growth & \\
\hline & FP4 & Gross profit at the last three years & \\
\hline & FP5 & Return on asset & 6 \\
\hline & FP6 & Return on investment & 0 \\
\hline & FP7 & Return on sales & \\
\hline & FP8 & Overall performance & \\
\hline \multirow[t]{5}{*}{ Strategy orientation (SO) } & SO1 & Our strategy is driven by our perception of opportunity & \\
\hline & $\mathrm{SO} 2$ & We pursue opportunity and then acquire resources & \\
\hline & SO3 & Opportunities control firm's business strategy & \\
\hline & SO4 & $\begin{array}{l}\text { We limit the opportunity that we pursue due to limited } \\
\text { resources (R) }\end{array}$ & \\
\hline & SO5 & Our resources influence our business strategy (R) & \\
\hline \multirow{5}{*}{$\begin{array}{l}\text { Technological turbulence } \\
\text { (Tech) }\end{array}$} & ET1 & Information technology in our industry changes rapidly & \\
\hline & ET2 & Information technology in our industry provides opportunity & \\
\hline & ET3 & $\begin{array}{l}\text { Information technological generates new product ideas to } \\
\text { our business }\end{array}$ & \\
\hline & ET4 & Information technology generates new ideas from product supply & Table I. \\
\hline & ET5 & Information technology generates new ideas to our business & The measures \\
\hline
\end{tabular}

asset less than Rp50 million. The a small business is a firm with asset between Rp50 million and 500 million as well as sales between Rp300 million and Rp2.5 billion per annum, while medium enterprise is a firm with annual sales from 2.5 billion to Rp50 billion. Hence, the business units with such criteria become major target group for local governments to promote entrepreneurship program.

This research employs random sample from the 35,489 observed population. Sampling frame, which is a list of population elements from which units to be sampled can be selected, refers to the database about SMEs published by Indonesian Government between 2010 and 2012. After identifying and defining the population at the previous step, the first step for simple random sampling is about determining the desired sample size. According to Krejcie and Morgan (1970), a sample size for representative of population with number between 30,000 and 50,000 is about 380 .

After the questionnaires are randomized distributed and data screening is carried out, the study utilizes 390 data from various industries contribute to the research. The respondents represent various important positions at the firms: 213 people are owner managers, 95 are owners, 39 managers, and 42 are senior staffs. Those firms work at various industries, i.e. food processing, manufacture, construction, trading, restaurant, and services. Most of them come from trading and food processing, 189 and 72 firms, respectively. In addition, there are 66 restaurants and 24 construction firms, followed by 21 services and 14 manufacture. Other four companies work at urban farming sector.

\subsection{Research design}

This study uses subjective approach to identify SME performance, which is part of research strategy to deal with viable financial report of SMEs (Sheppard and Radulovich, 2010). This study considers that a firm has two options for SO, whether focus on internal resources or opportunities. Opportunity-driven strategy pertains to firm responsiveness to emerging issues raised by stakeholders. Staying ahead of 
BPMJ

22,2

innovation is critical to establishing and extending a competitive advantage for SMEs, and that technology is key in innovation strategy.

The measures of SO are adapted from Gürbüz and Aykol (2009) and Bradley et al. (2012). The measures of TT are adapted from Zhang and Duan (2010) and Didonet et al. (2012). Given to technology turbulence, Zhang and Duan (2010) and Chi and Sun (2013) consider three measures of technology turbulence: the speed of technological change; opportunities from technological change; new products from changing technology. In addition, Didonet et al. (2012) add the impact of technology change of supplier. To gain valuable information from the local context, those questionnaires are translated into local language with support from local experts.

This study uses partial least square (PLS) for statistical analysis and hypothesis testing. Hair et al. (2012) argue that PLS-SEM is still relevant to handle reflective and formative measures without identification concerns. This approach focusses on prediction with resampling procedure and non-parametric evaluation criteria to analysis the adequacy of partial model structure. According to Henseler et al. (2009), the popularity of PLS-SEM springs from four characteristics. First, the approach allows unrestricted computation of structural equation model with reflective and formative measurements. Second, small sample size is still acceptable without leading to estimation problem, even with complex models. Third, PLS can deal with highly skewed data distribution (Hair et al, 2012).

Moderating variable may bring change direction on the slope or coefficient of independent variables. Moderating effect may dampen the positive effect of the independent variables on FP (Henseler and Fassott, 2010). In structural equation model (SEM), the formulation of moderating effect of TT on the relationship between $\mathrm{SO}$ and FP can be expressed as bellow:

$$
\begin{gathered}
F P=a+b S O \\
F P=a+(b+d \times T e c h) \times S O+c T e c h \\
=(a+c \times T T)+(b+d \times T T) \times S O
\end{gathered}
$$

\section{Finding and analysis}

Table I shows the respondent profile and performance. The profile includes asset, sales, and sectors. The performance measures show that 1 indicating much lower performance and 7 indicating much higher performance. The performance indicates 7 level of overall performance based on subjective measures. The amount of asset and sales refer to the Indonesian Law, regarding the SME criteria.

Based on asset, the study indicates that most of the observed firms are medium enterprises (242 units). They represent 62 percent of total observed firms, while 120 firms represent small enterprises and the rest represent micro enterprises (28 units). Based on annual sales, most of the observed firms represent small firms. They represent 67 percent of total observed firms. Hence, 76 firms are considered to be micro enterprises, while 52 represent medium enterprises. The subjective measure of performances indicates that 18 firms with asset between IDR2.5 billion and IDR10 billion state that they experience very low performance, while only one firm with sales between IDR2.5 billion and IDR50 billion has very low performance.

The observation indicates that most of the observed firms represent trading sector with 189 firms, followed by agricultural firms with 72 unit, restaurant with 66 units, 
and construction firms with 24 units. In each sector, most of them experience high performance with 5-6 level from 7 scales of performance. Those who argue that their performance is much lower come from agricultural sector. However this not represent all firms that work in agriculture. In fact, 24 agricultural firms state that their performance is quite higher with 6 levels from 7 scale of performance.

Table II shows the summary of a set of variables structure. This study considers average variance extracted (AVE), composite reliability (CR) and Cronbach's $\alpha(\mathrm{CA})$. It appears that all latent variables have AVE greater than 0.50, which implies that convergent validity is accepted. Thereafter, CRs are greater than 0.80 , indicate that measures are reliable, while CAs are greater than 0.6 , which shows that the measures of all latent variables are consistent.

The cross-loading factors show correlation of the component scores of each latent variable with other items. A successful evaluation of discriminant validity shows that a test of a concept is not highly correlated with other tests designed to measure theoretically different concepts. Table III provides evident that the measures of each item explains designation latent variable at greater value than 0.6 , which indicates high correlation of each items for its corresponding construct than other constructs, which implies that the variation of each item are great enough to explain the designated latent

\begin{tabular}{|c|c|c|c|c|c|c|c|c|}
\hline \multirow[b]{2}{*}{ Overall performance } & \multicolumn{7}{|c|}{ Performance } & \\
\hline & 1 & 2 & 3 & 4 & 5 & 6 & 7 & \\
\hline \multicolumn{9}{|l|}{ Firm assets } \\
\hline Less than IDR50 million & 1 & 1 & 0 & 2 & 6 & 12 & 6 & \\
\hline Between IDR50 and IDR500 million & 13 & 2 & 3 & 16 & 33 & 35 & 18 & \\
\hline Between IDR500 million and IDR10 billion & 18 & 6 & 8 & 31 & 55 & 91 & 33 & \\
\hline Total & 32 & 9 & 11 & 49 & 94 & 138 & 57 & \\
\hline \multicolumn{9}{|l|}{ Firm sales } \\
\hline Less than IDR300 million & 6 & 2 & 2 & 6 & 26 & 19 & 15 & \\
\hline Between IDR300 and IDR2.5 billion & 25 & 5 & 8 & 36 & 49 & 105 & 34 & \\
\hline Between IDR2.5 billion and IDR50 billion & 1 & 2 & 1 & 7 & 19 & 14 & 8 & \\
\hline Total & 32 & 9 & 11 & 49 & 94 & 138 & 57 & \\
\hline \multicolumn{9}{|l|}{ Sector } \\
\hline Agriculture & 16 & 1 & 2 & 4 & 19 & 24 & 6 & \\
\hline Manufacture & 0 & 0 & 1 & 2 & 5 & 5 & 1 & \\
\hline Construction & 1 & 0 & 0 & 4 & 12 & 12 & 3 & \\
\hline Trade & 8 & 6 & 5 & 26 & 71 & 71 & 32 & \\
\hline Restaurant & 4 & 1 & 2 & 9 & 22 & 22 & 11 & \\
\hline Rental & 2 & 1 & 1 & 4 & 3 & 3 & 4 & \\
\hline Services & 1 & 0 & 0 & 0 & 1 & 1 & 0 & Table II. \\
\hline Total & 32 & 9 & 11 & 49 & 94 & 138 & 57 & Respondent profile \\
\hline
\end{tabular}

\begin{tabular}{lcccccrr}
\hline & AVE & CR & $R^{2}$ & CA & Communality & Redundancy & \\
\hline FP & 0.658061 & 0.920145 & 0.397210 & 0.895915 & 0.658061 & 0.121839 & \\
SO & 0.647511 & 0.783345 & & 0.692353 & 0.647511 & & Table III. \\
SO $\times$ Tech & 0.659308 & 0.958699 & & 0.953041 & 0.659308 & & A set of variable \\
Tech & 0.729805 & 0.915275 & & 0.876708 & 0.729805 & & structure \\
\hline
\end{tabular}

$\begin{array}{r}\text { Strategic } \\ \text { orientation and } \\ \text { information } \\ \text { TT } \\ \mathbf{8} \\ \hline\end{array}$


BPMJ

22,2

9

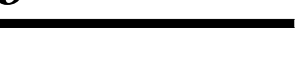

variable. Specifically, EO and SO have items with cross-loadings are greater than 0.8 . Table 48 shows that loadings of the observed constructs are greater than for any of other constructs. The loading of each indicator is higher for its designated construct than for any of the other constructs, and each of the constructs loads highest with its own items, it can be inferred that the models' constructs differ sufficiently from one another.

Table IV provides path analysis. The result indicates that $H 1$ is accepted with $t$-test 4.05 or greater than $t$-table and $\alpha<0.01$. This indicates that the greater SO may bring greater FP. The relationship between Tech and FP as well as interaction effect also have significant with $\alpha<0.5$ percent. This indicates that TT has moderating effect on the relationship between SO and FP (Table V).

Figure 1 shows that TT brings different impact on FP. Under low TT, SO has positive impact with FP (solid line). This implies that the observed SMEs can gain greater performance with low environmental turbulence. On the other hand, high TT changes the positive relationship into the negative one. This indicates the observed SMEs suffer from high TT (Figure 2).

\begin{tabular}{|c|c|c|c|c|}
\hline & FP & SO & $\mathrm{SO} \times \mathrm{Tech}$ & Tech \\
\hline SO01 & & 5.852986 & & \\
\hline SO01 ×ET01 & & & 21.988844 & \\
\hline $\mathrm{SO} 01 \times \mathrm{ET} 02$ & & & 20.766365 & \\
\hline $\mathrm{SO} 01 \times \mathrm{ET} 03$ & & & 13.473726 & \\
\hline SO01×ET05 & & & 15.975984 & \\
\hline SO03 & & 7.141474 & & \\
\hline $\mathrm{SO} 03 \times \mathrm{ET} 01$ & & & 15.919710 & \\
\hline SO03 $\times$ ET0 2 & & & 18.330485 & \\
\hline $\mathrm{SO} 03 \times \mathrm{ET} 03$ & & & 13.354890 & \\
\hline $\mathrm{SO} 03 \times \mathrm{ET} 05$ & & & 16.452373 & \\
\hline SO05 & & 12.342448 & & \\
\hline $\mathrm{SO} 05 \times \mathrm{ET} 01$ & & & 27.898543 & \\
\hline SO05 × ET02 & & & 21.352244 & \\
\hline $\mathrm{SO} 05 \times \mathrm{ET} 03$ & & & 17.140548 & \\
\hline SO05 × ET05 & & & 22.438821 & \\
\hline ET01 & & & & 26.498320 \\
\hline ET02 & & & & 21.355966 \\
\hline ET03 & & & & 18.539311 \\
\hline ET05 & & & & 18.455091 \\
\hline FP02 & 16.497003 & & & \\
\hline FP04 & 8.107064 & & & \\
\hline FP05 & 12.458960 & & & \\
\hline FP06 & 21.174287 & & & \\
\hline FP07 & 20.081278 & & & \\
\hline FP08 & 13.239880 & & & \\
\hline
\end{tabular}

Table IV.

Outer model $t$-statistic

\begin{tabular}{lcrrrr}
\hline & Original sample & Sample mean & SD & SE & $t$-statistics \\
\hline SO $\rightarrow$ FP & 0.648808 & 0.617660 & 0.159905 & 0.159905 & 4.057459 \\
SO $\times$ Tech $\rightarrow$ FP & -0.720752 & -0.679672 & 0.322378 & 0.322378 & 2.235734 \\
Tech $\rightarrow$ FP & 0.915508 & 0.909080 & 0.247779 & 0.247779 & 3.694861
\end{tabular}



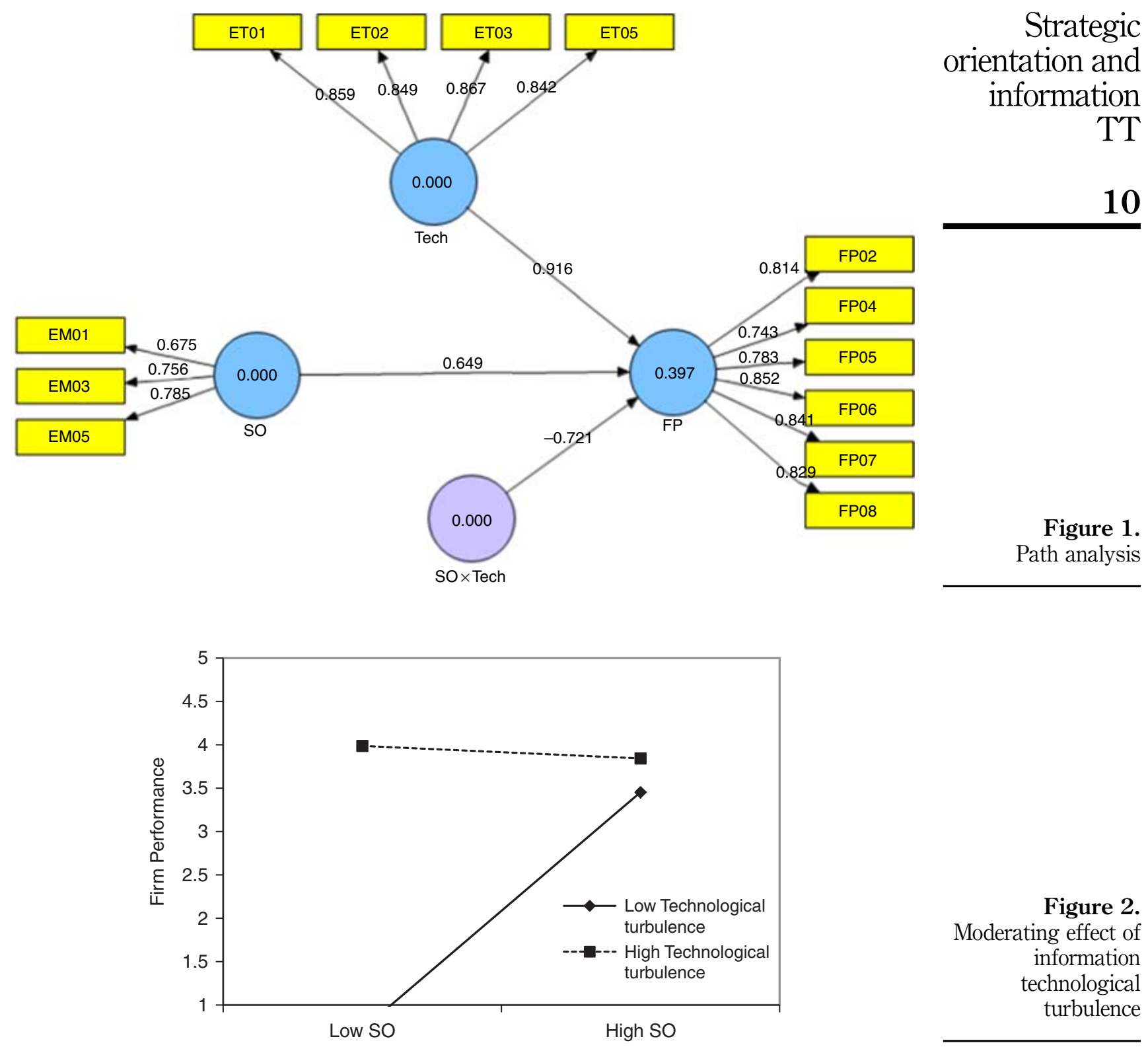

Figure 1. Path analysis

Figure 2.

Moderating effect of information technological turbulence

\section{Discussion}

It appears that IT provides challenges for SME performance. The turbulence represents a process that alters the impact of the independent variables on $\mathrm{FP}$ in the context of contingency theory. SMEs with greater SO can increase their performance in certain condition. However, the wide range of dynamic TT provides different impact on the relationship between SO and FP.

Moderate TT allows the observed SMEs with opportunity-based strategic posture to achieve their performance. This condition indicates that under predictable technological change, the SMEs can utilize technology to implement their strategy. However, under very dynamic technology turbulence, SMEs will suffer from opportunity-driven strategy. This indicates that there is a scale of absorptive capacity of the SMEs to utilize technology (Alexy et al., 2013). 
BPMJ

22,2

Rapid and significant information technological changes in an industry reflect TT. A firm might have strong SO, but it requires capability to deal with TT. TT brings more uncertainty business environment to the SMEs. Thus, technological capability in a low TT context is more relevant than it has in a high TT context.

The managerial implication indicates that IT can solve the problem of SMEs by creating online outlet. Typically, SME managers often lack awareness to understand the business contingency process. This severe problem occurs when crisis hit the organization (Linström, 2012). Hence, the contingency approach encourages SME managers and their organizations respond it by conducting training. This approach has been used to examine the solution in various industries, e.g. SMEs and public organization in different national cultures (Jääskelainen, et al., 2012).

In the context of public policy, the initiative to promote such technology needs to consider the capacity of SMEs. IT may become valuable resources, but the process of transforming such resources to greater performance needs greater capacity, which implies greater scale of economy. Firms facing significant and persistent technological changes can adapt by utilizing their technological capabilities. In contrast, under low TT, they do not face such serious demands to respond to technological changes.

It is more appropriate for the SMEs operating in stable technological change to adopt SO, which lays emphasis on greater intention for business opportunities, while firms in more dynamic technological settings should consider their capacity to manage their resources. The result indicates that implementing strategy is in essence an investment project requires resources commitment and corresponding adjustment of organizational capability. A firm requires multiple partners to maximize the benefit of technology (Alexy et al., 2013). Hence, future study may explore the capability of SMEs to maximize the benefit of such technology as they go partnership.

SMEs need to understand the extent of information technological change, before they set a specific SO whether by opportunities or by resources-based orientation (Zhao et al., 2010). This implies that the initiative respond to exploit market opportunity of firms, which called as proactiveness (Covin and Lumpkin, 2011), is fluctuated over time. This marketing capability is acknowledged as valuable resources to SMEs (Pratono and Mahmood, 2015). Hence, future research on SMEs may address the intersection between information TT and dynamic marketing capability.

Stable TT allows proactive behavior to achieve the best FP; while firms with proactive behavior will suffer from poor performance under dynamic TT. Dynamic TT encourages firms to take risk aversion behavior by setting a strategy with resourcebased orientation. This result supports the previous argument that entrepreneurial behavior is dynamically adapted to TT (Zellweger and Sieger, 2012).

The cross-section data in Indonesia SME context is considered to be the limitation of this study, which implies on snap shoot observation. Hence, the future studies may examine the similar issue with relevant panel data analysis in different countries and different environment context. In addition, this study relies on one source of information in each firm. The future studies may involve various stakeholders to confirm the firm behavior in every business organization.

\section{Conclusion}

It appears that prevalent capabilities intertwined with organizational boundaries and provides valuable extension for the perspective of contingency theory, which explains on how SMEs deal with information technological changes. This study draws conclusion to argue that SO on business opportunity comes to limitation under 
information TT. Recognizing the moderating effect of information TT on the relationship between SO and FP allows clarifying the key contingency of FP.

This study confirms heterogeneous relationship between return of SO and FP. The dynamic capability offers more complicated effects on SMEs with concern to gain market opportunities under various dynamic TTs. SMEs may make substantial investment in R\&D to seize the opportunity but they may suffer from poor performance under high TT

SME performance may stems from opportunity-based strategy but it also contingent on information TT. The result shows how the TT influences managerial decision-making processes under an opportunity-based paradigm. In particular, high TT is the largest driver of responsive market orientation, while competitive intensity is the most significant driver of proactive market orientation. However, SME managers seem to face lack of capability to deal with high TT.

The finding should encourage SME managers and policy makers to pay concern in technological capability that will allow SMEs to gain sustainable competitive advantage. Indeed, the concept such as opportunity recognition and dynamic capability are central to the success of SMEs, especially with entrepreneurial behavior. As the study concerns on the impact of TT on the relationship between SO and FP, the review on generic contingency factors briefly discuss to illustrate their significance.

\section{References}

Alexy, O., George, G. and Salter, A. (2013), "Cui bono? The selective revealing of knowledge and its implications for innovative activity", Academy of Management Review, Vol. 38 No. 2, pp. 270-290.

Barney, J. (1991), "Firm resources and sustained competitive advantage", Journal of Management, Vol. 17 No. 1, pp. 99-120.

Q4 Bazemer, P.-J., Peij, S., Maasen, G. and van Halder, H. (2012), "The changing role of the supervisory board chairman: the case of the Netherlands (1997-2007)", Journal of Management Governance, Vol. 16, pp. 37-55.

Bell, R. and Martin, J. (2012), "The relevance of scientific management and equity theory in everyday managerial communication situations", Journal of Management Policy and Practice, Vol. 13 No. 3, pp. 106-115.

Betta, M., Jones, R. and Latham, J. (2010), "Entrepreneurship and the innovative self: a schumpeterian reflection", International Journal of Entrepreneurial Behaviour \& Research, Vol. 16 No. 3, pp. 229-244.

Bradley, S., Wiklund, J. and Shepherd, D. (2011), "Swinging a double-edged sword: the effect of slack on entrepreneurial management and growth", Journal of Business Venturing, Vol. 26 No. 5, pp. 537-554.

Bundy, J., Shropshire, C. and Buchholtz, A. (2013), "Strategic cognition and issue salience: toward an explanation of firm responsiveness to stakeholder concerns", Academy of Management Review, Vol. 38 No. 3, pp. 352-376.

Cao, G., Wiengarten, F. and Humphreys, P. (2011), “Toward a contingency resource-based view of IT business value", Systemic Practice and Action Research, Vol. 24, pp. 85-106.

Chi, T. and Sun, Y. (2013), "Development of firm export market oriented behavior: evidence from an emerging economy", International Business Review, Vol. 22, pp. 339-350.

Q5 Covin, J. and Lumpkin, G. (2011), "Entrepreneurial orientation theory and research: reflection on a needed construct", Entrepreneurship Theory and Practice, pp. 855-872.

Cui, A. (2013), "Portfolio dynamics and alliance termination: the contingent role of resource dissimilarity", Journal of Marketing, Vol. 77 No. 5, pp. 15-32. orientation and information

TT 
BPMJ

22,2

13

Didonet, S., Simmons, G., Díaz-Villavicencio, G. and Palmer, M. (2012), "Firms with capability to leverage substantial technological resources to come up innovation", Marketing Inteligence \& Planning, Vol. 30 No. 7, pp. 757-779.

Donaldson, L. (1995), American Anti-Management Theories of Organization: A Critique of Paradigm Proliferation, Cambridge University Press, Cambridge.

Eisenhardt, K. and Martin, J. (2000), "Dynamic capabilities: what are they?", Strategic Management Journal, Vol. 21, pp. 1105-1121.

Gürbüz, G. and Aykol, S. (2009), "Entrepreneurial management, entrepreneurial orientation and Turkish small firm growth”, Management Research News, Vol. 32 No. 4, pp. 321-336.

Homburg, C., Artz, M. and Wieseke, J. (2012), "Marketing performance measuremant systems: does comprehensiveness really improve performance?", Journal of Marketing, Vol. 76 No. 5, pp. 56-77.

Huesch, M. (2013), "Are there always synergies between productive resources and resource deployment capabilities?”, Strategic Management Journal, Vol. 34, pp. 1288-1313.

Jääskelainen, A., Laihonen, H., Lönnqvist, A., Palvalin, M., Sillanpää, V., Perkkola, S. et al. (2012), "A contingency approach to performance measurement in service operations", Measuring Business Excellence, Vol. 16 No. 1, pp. 43-52.

Johannesson, J. and Palona, I. (2010), "Environmental turbulence and success of firm's intelligence strategy: development of research instruments", International Journal of Management, Vol. 27 No. 3, pp. 448-458.

Kansikas, J., Laakkonen, A., Sarpo, V. and Kontinen, T. (2012), "Entrepreneurial leadership and familiness as resources for strategic entrepreneurship", International Journal of Entrepreneurial Behavior \& Research, Vol. 8 No. 2, pp. 141-158.

Kapoor, R. and Lee, J. (2013), "Coordinating and competing in ecosystems: how organizational forms shape new technology investment”, Strategic Management Journal, Vol. 34, pp. 274-296.

Klingebiel, R. and Rammer, C. (2014), "Resource allocation strategy for innovation portfolio management", Strategic Management Journal, Vol. 35, pp. 246-268.

Kumar, V., Jones, E., Venkatesan, R. and Leone, R. (2011), "Is market orientation a source of sustainable competitive advantage or simply the cost of competing?", Journal of Marketing, Vol. 75 No. 1, pp. 16-30.

Kunc, M. and Morecroft, J. (2010), "Managerial decision making and firm performance under a resource-based paradigm", Strategic Management Journal, Vol. 31, pp. 1164-1182.

Li, Q., Smith, K., Tesluk, P. and Katila, R. (2013), "Top management attention to innovation: the role of search selection and intensity in new product introductions", Academy of Management Journal, Vol. 56 No. 3, pp. 893-916.

Lim, D., Celly, N., Morse, E. and Rowe, G. (2013), "Rethinking the effectiveness of asset and cost retrenchment: the contingency effect of firm's rent creation mechanism", Strategic Management Journal, Vol. 34, pp. 42-61.

Linström, J. (2012), “A model to explain a business contingency process”, Disaster Prevention and Management, Vol. 21 No. 2, pp. 269-281.

Luo, X., Andrews, M., Song, Y. and Aspara, J. (2014), “Group-buying deal popularity”, Journal of Marketing, Vol. 78 No. 3, pp. 20-33.

McGrath, R. (2013), The End of Competitive Advantage, Harvard Business Review Press, Boston, MA.

Mintzberg, H. and Waters, J. (1985), "Of strategies, deliberate and emergent", Strategic Management Journal, Vol. 6, pp. 257-272.

Park, R. and Kruse, D. (2014), "Group incentives and financial performance: the moderating role of innovation”, Human Resource Management Journal, Vol. 24 No. 1, pp. 77-94. 
Penrose, E. (1959), The Theory of the Growth of the Firm, Oxford University Press, Oxford.

Pheng, L. and Shang, G. (2011), "Bridging Western management theories and Japanese management practices: case of the Toyota way model", Emerald Emerging Market Case Studies, Vol. 1 No. 1, pp. 1-20.

Pratono, A. and Mahmood, R. (2015), "Mediating effect of marketing capability and reward philosophy in the relationship between entrepreneurial orientation and firm performance", Journal of Global Entrepreneurship Research, Vol. 5 No. 5, pp. 1-12.

Strategic orientation and information

Puranam, P., Alexy, O. and Reitzig, M. (2014), "What's 'new' about new forms of organizing?", Academy of Management Review, Vol. 39 No. 2, pp. 162-180.

Risselada, H., Verhoef, P. and Bijmolt, T. (2014), "Dynamic effects of social influence and direct marketing onthe adoption of high-technology product", Journal of Marketing, Vol. 78 No. 3, pp. 52-68.

Ruiz-Ortega, M., Parra-Requena, G., Rodrigo-Alarcón, J. and García-Villaverde, P. (2013), "Environmental dynamism and entrepreneurial orientation: the moderating role of firm's capability", Journal of Organizational Change Management, Vol. 26 No. 3, pp. 475-493.

Schilke, O. (2014), "On the contingent value of dynamic capabilities for competitive advantage: the nonlinear moderating effect of environmental dynamism", Strategic Management Journal, Vol. 35, pp. 179-203.

Sundqvist, S., Kyläheiko, K., Kuivalainen, O. and Cadogan, J. (2012), "Kirznerian and Schumpeterian entrepreneurial-oriented behavior in turbulent export markets", International Marketing Review, Vol. 29 No. 2, pp. 203-209.

Wang, M.-C. and Fang, S.-C. (2012), "The moderating effect of environmental uncertainty on the relationship between network structures and the innovative performance of a new venture", Journal of Business and Industrial Marketing, Vol. 27 No. 4, pp. 311-323.

Wiesner, R. and Millet, B. (2012), "Strategic approaches in Australian SMEs: deliberate or emergent?", Journal of Management and Organization, Vol. 18 No. 1, pp. 98-122.

Wu, B., Wan, Z. and Levinthal, D. (2014), "Complementary assets as pipes and prisms: innovation incentives and trajectory choices", Strategic Management Journal, Vol. 35, pp. 1257-1278.

Zellweger, T. and Sieger, P. (2012), "Entrepreneurial orientation in long-lived family firms", Small Business Economics, Vol. 38, pp. 67-84.

Zhang, J. and Duan, Y. (2010), "The impact of different types of market orientation on product innovation performance", Management Decision, Vol. 48 No. 6, pp. 849-867.

Zhao, X., Lynch, J. and Chen, Q. (2010), "Reconsidering Baron and Kenny: myths and truths about mediation analysis", The Journal of Consumer Research, Vol. 37 No. 2, pp. 197-206.

\section{Further reading}

Pearson, A., Carr, J. and Shaw, J. (2008), "Toward a theory of familiness: a social capital perspective", Entrepreneurship Theory and Practice, Vol. 32 No. 6, pp. 949-969.

Wales, W., Gupta, V. and Moussa, F. (2011), "Empirical research on entrepreneurial orientation: an assessment and suggestions for future research", International Small Business Journal, Vol. 31 No. 4, pp. 357-383.

\section{Corresponding author}

Aluisius Hery Pratono can be contacted at: hpratono@yahoo.com

For instructions on how to order reprints of this article, please visit our website:

www.emeraldgrouppublishing.com/licensing/reprints.htm

Or contact us for further details: permissions@emeraldinsight.com 